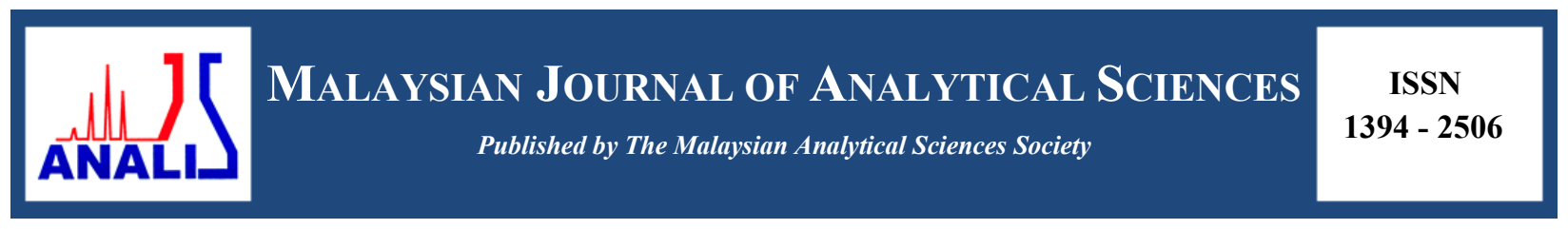

\title{
PREPARATION AND CHARACTERIZATIONS OF POLY(ANILINE-co-m- AMINOBENZOIC ACID)/POLYSTYRENE COMPOSITE NANOFIBERS AND FILMS
}

\author{
(Penyediaan dan Pencirian Poli(Anilina-ko-m-Asid Aminobenzoik)/Polistirena Komposit Fiber \\ Nano dan Filem)
}

Fatimah Syahidah Mohamad and Norizah Abdul Rahman*

Department of Chemistry,

Universiti Putra Malaysia, 43400 Serdang, Selangor, Malaysia

*Corresponding author: a_norizah@upm.edu.my

Received: 17 August 2015; Accepted: 17 June 2016

\begin{abstract}
In this research, a simple method was used to synthesize poly(aniline-co-m-aminobenzoic acid) also known as $\mathrm{P}(\mathrm{ANI}-\mathrm{co}$ - $m$ ABA) composite polystyrene (PS) nanofibers by using in situ chemical polymerization technique. The copolymer was polymerized on electrospun PS nanofibers mats with varied monomers solution concentration and the polymerization time. $\mathrm{P}(\mathrm{ANI}-\mathrm{co}-\mathrm{m}$-ABA) was also polymerized on PS films were prepared for comparison. The conductivity of the composites was studied and the result showed addition of graphene (GP) into the composites improved the conductivity of the composites. The composites of P(ANI-co-m-ABA)/PS nanofibers and films were characterized by Fourier transform infra-red (FTIR), thermogravimetric analysis (TGA) and ultraviolet visible (UV-vis) spectroscopy. Surface morphology of the composite was studied by scanning electron microscopy (SEM).
\end{abstract}

Keywords: poly(aniline-co-m-aminobenzoic acid), nanofibers, electrospinning

Abstrak

Dalam kajian ini, satu cara mudah telah digunakan untuk sintesis poli(anilina- $k o-m$-asid aminobenzoik) atau diringkas sebagai $\mathrm{P}(\mathrm{ANI}-\mathrm{co}-\mathrm{m}$-ABA) komposit polistirena (PS) fiber nano dengan menggunakan teknik pempolimeran kimia in situ. Pempolimeran kopolimer telah dijalankan ke atas PS fiber nano pada kepekatan monomer dan masa pempolimeran yang berbeza. P(ANI-co-m-ABA) juga menjalani proses pempolimeran ke atas filem PS sebagai perbandingan. Konduktiviti komposit telah dikaji dan keputusan menunjukkan dengan penambahan grafin (GP) ke dalam filem PS, bacaan konduktiviti elektrik telah meningkatkan. Komposit P(ANI-co-m-ABA) dan fiber nano PS telah dicirikan dengan menggunakan spektroskopi inframerah transformasi Fourier (FTIR), analisis termogravimetri (TGA) dan spektroskopi ultraungu nampak (UV-vis). Morfologi komposit juga telah dikaji dengan menggunakan mikroskopi elektron imbasan (SEM).

Kata kunci: poli(anilina-ko-m-asid aminobenzoik), fiber nano, putaran elektro

\section{Introduction}

PANI is one of the most studied conducting polymers due to its high electronic conductivity, redox and ionexchange properties, excellent environmental stability and ease of preparation from common chemicals. The utilization of homopolymer PANI in industrial and technological application is hampered by its poor processability and miscibility due to low solubility [1]. The synthesizing copolymer of aniline and substituted aniline with 
carboxylic acid is one of the attempts that have been made in order to increase its processability. Acid functionalize PANI such as $\mathrm{P}(\mathrm{ANI}-\mathrm{co}-\mathrm{m}-\mathrm{ABA})$ was prepared chemically by adding the aniline with co-monomer, in this case is $m$-aminobezoic acid $(m-\mathrm{ABA})$. The incorporation of functional group $(\mathrm{COOH})$ into polymer backbone gives different properties from those of PANI in terms of lower conductivity with increasing solubility [2].

Meanwhile, PS nanofiber have received attention due to their unique properties such as low density, large surface area to mass, and high pore volume with controllable pore size [3]. In recent years, PS nanofibers have been fabricated by electrospinning technique. The electrospun PS nanofibers have a good macromolecular orientation along the fibers direction, which is produced by stretching of the polymer jet during electrospinning. The high molecular orientation of polymer molecules in the electrospun nanofibers enhances their mechanical properties (e.g. higher elastic modulus and strength) as compared to bulk material [4]. Therefore, the composite of P(ANI-co-m$\mathrm{ABA})$ and PS nanofiber can enhace the properties of both polymers.

GP is known for its very low weight and great efficiency in conduction of both and electricity [5]. Due to graphene's exceptional thermal, mechanical and electrical properties, it stands out as the most promising candidate to be a major filling agent for composite applications. GP nanocomposites at very low loading show substantial enhancements in their multifunctional aspects, compared to conventional composites and their materials. This not only makes the material lighter with simple processing, but also makes it stronger for various multifunctional applications. The remarkable properties of GP are able to improve the physicochemical qualities of the host matrix upon distribution [6].

The aim of this study is to prepare the poly(aniline-co-m-aminobenzoic acid) composite polystyrene (PS) nanofibers by using in situ chemical polymerization technique and characterize their physical and chemical properties.

\section{Materials and Methods}

\section{Materials}

Aniline was purchased from Fischer Chemical. The aniline was purified by distillation and hermetically sealed in the absence of light. The co-monomers, $m$-ABA, and oxidizing agent, APS $\left(\left(\mathrm{NH}_{4}\right)_{2} \mathrm{~S}_{2} \mathrm{O}_{2}\right)$ with purity $97 \%$ was supplied by Merck Schuchardt OHG. Solvents used namely dimethyl-formamide (DMF) and tetrahydrofuran (THF) were purchased from the Fischer Chemical.

\section{Preparation of PS nanofibers}

Electrospinnable solutions was obtained by dissolving $0.2 \mathrm{~g}$ of PS in THF/DMF (1:1) Then, the PS solution was filled in a $5 \mathrm{~mL}$ syringe attached with a blunt steel needle of $0.8 \mathrm{~mm}$ inner diameter. A square box covered with aluminium foil was placed $10 \mathrm{~cm}$ away from the needle tip as counter electrode. Electrospinning was carried out at room temperature in a horizontal spinning configuration, using the applied voltages $8 \mathrm{kV}$, driven by a high voltage power with a flow rate of $1 \mathrm{~mL} / \mathrm{h}$. The aluminum foil was placed over the counter electrode as collecting substrate.

\section{Preparation of PS and PS/GP films}

The preparation of PS/graphene film was similar to the preparation of PS nanofibers. An amount $10 \mathrm{wt}$ \% of PS thin film was prepared by stirring $0.2 \mathrm{~g}$ of PS in $2 \mathrm{~mL}$ of THF/DMF (1:1) using a magnetic bar until PS completely dissolved. The polymer solution was poured into the petri dish and left for air dried overnight. Then, the thin PS film was cut into $5 \mathrm{~cm} \times 1 \mathrm{~cm}$. PS/graphene film was prepared using $10 \mathrm{wt} \%$ PS solution added with $15 \mathrm{mg}$ of graphene powder and stirred until the whole mixture homogenously mixed together. The solution was poured into the petri dish and left for air dried overnight. The thickness of PS and PS/graphene films were measured using vernier caliper.

\section{Preparation of PS/P(ANI-co-m-ABA) composite via in-situ polymerization}

The PS nanofibers and film were cut into $5 \mathrm{~cm} \times 1 \mathrm{~cm}$ and put in the aniline and/or $m$-ABA solution for in situ polymerzation. The P(ANI-co-m-ABA) was synthesized at fixed ratio of aniline to $m$-ABA $1: 1$. APS (3.65 g) in 50 $\mathrm{mL}$ of $1 \mathrm{M} \mathrm{HCl}$ was added dropwise into $100 \mathrm{ml}$ of $1 \mathrm{M} \mathrm{HCl}$ containing aniline $(1.46 \mathrm{~mL})$ and $m$-ABA $(1.100 \mathrm{~g})$ at room temperature. The solution was stirred and left for 24 hours. The concentration of monomers (aniline and $m$ $\mathrm{ABA}$ ) in $\mathrm{HCl}$ was varied from $0.5 \mathrm{M}$ to $1.5 \mathrm{M}$ to obtain thin $\mathrm{P}(\mathrm{ANI}-\mathrm{co}-\mathrm{m}$-ABA) coated on PS film or nanofibers. 
The time of polymerization was also altered, 24 hours, 48 hours and 72 hours. After that, polymer composite was rinsed using deionized water and dried in oven at $40^{\circ} \mathrm{C}$ for a day.

\section{Characterization of composite polymer}

The morphologies of the products were investigated with a JEOL XL30S field emission scanning electron microscope (SEM). The samples for SEM were mounted on aluminium studs using adhesive graphite tape and sputter-coated with gold before analysis. Infrared spectra were measured in the range $200-2000 \mathrm{~cm}^{-1}$ on PANI pellets made with $\mathrm{KBr}$ at a Perkin Elmer 1600 FTIR spectrophotometer, taking 10 scans at a resolution of $4 \mathrm{~cm}^{-1}$. Two-probe resistivity and hall voltage measurements with the model Kethley 2611-SMU is used to determine the resistivity of the sample. Two-point probe technique is used to measure the conductivity of the polymer. The sample is put on the holder and two probes was stick on the sample. A graph of current against voltage was plotted throughout this technique. Thermal gravimetric analysis (TGA) Mettler Toledo Star SW 7.01 was used. The sample was purged with nitrogen gas with a flow rate of $50 \mathrm{ml} / \mathrm{min}$ and the sample was heated from ambient temperature to $700{ }^{\circ} \mathrm{C}$ with heating rate $10^{\circ} \mathrm{C} / \mathrm{min}$.

\section{Spectroscopic study of PS/P(ANI-co-m-ABA) composite film}

\section{Results and Discussion}

Figure 1 and 2 show the UV-Vis spectra of the P(ANI-co-m-ABA) with different monomers concentrations and polymerization times. The UV-Vis spectra as shown in figure 1 and 2 display two main absorption peaks at $225-$ $325 \mathrm{~nm}$ and $465-565 \mathrm{~nm}$. The first peak contributed to $\pi \rightarrow \pi^{*}$ transition and significant to extended conjugation in polymer chain [7]. The copolymer undergoes blue shifted as the concentration of monomers used in the polymerization lower due to the less conjugated property and belongs high energy. The second peak in between 465 $-565 \mathrm{~nm}$ attributed to the transition of exciton of quinine due to the inter- and intrachain charge transfer [8]. The hypsochromic shift in copolymer is due to the carboxylic interruption in polymer chain as mentioned before, in which give implication to its conductivity property. The behavior of copolymer that proved in this UV-Vis is in agreement with the conductivity measurement results in which suggest that higher concentrations of monomers will decrease the conductivity property in copolymer.

In $\mathrm{P}(\mathrm{ANI}-\mathrm{co}-\mathrm{m}$-ABA) there is hypsochromic shift and hypochromic shift display due to the incorporation of $m$ ABA into backbone of parent structure. This phenomenon can be explained by the increasing of steric repulsion between adjacent groups as consequences of carboxylic acid group from $m$-ABA substituent addition that lead to the twisting of the polymer chain. Indirectly, this situation will lower the degree of co-planarity and interrupt the conjugation of the polymer rings, as well as increase the transition energy.

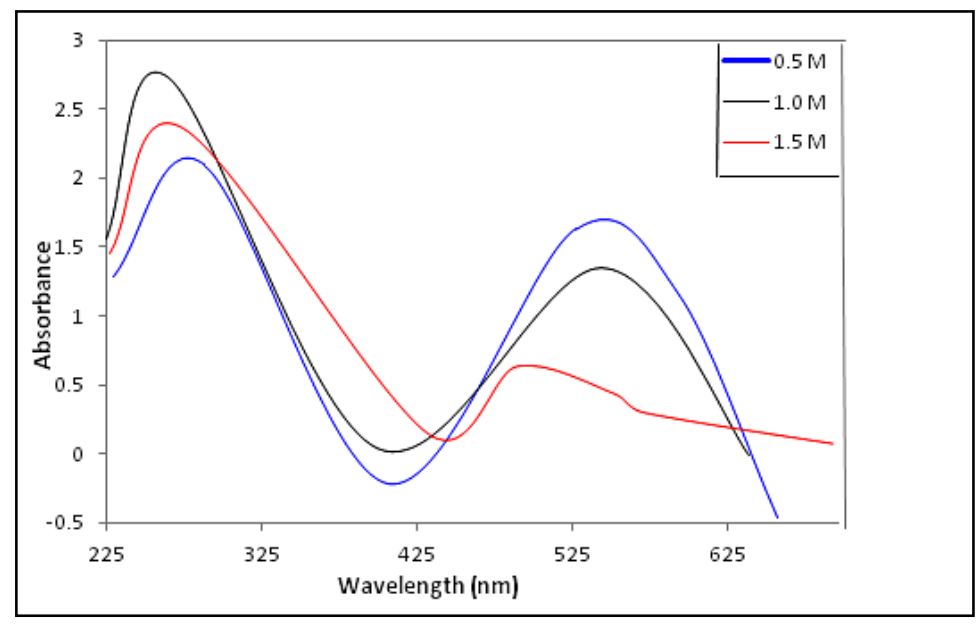

Figure 1. UV-Vis spectra of $\mathrm{P}(\mathrm{ANI}-\mathrm{co}-\mathrm{m}-\mathrm{ABA})$ synthesized with monomers concentrations of $0.5 \mathrm{M}, 1.0 \mathrm{M}$ and $1.5 \mathrm{M}$, respectively 
Fatimah Syahidah \& Norizah: PREPARATION AND CHARACTERIZATIONS OF POLY(ANILINE-co-mAMINOBENZOIC ACID)/POLYSTYRENE COMPOSITE NANOFIBERS AND FILMS

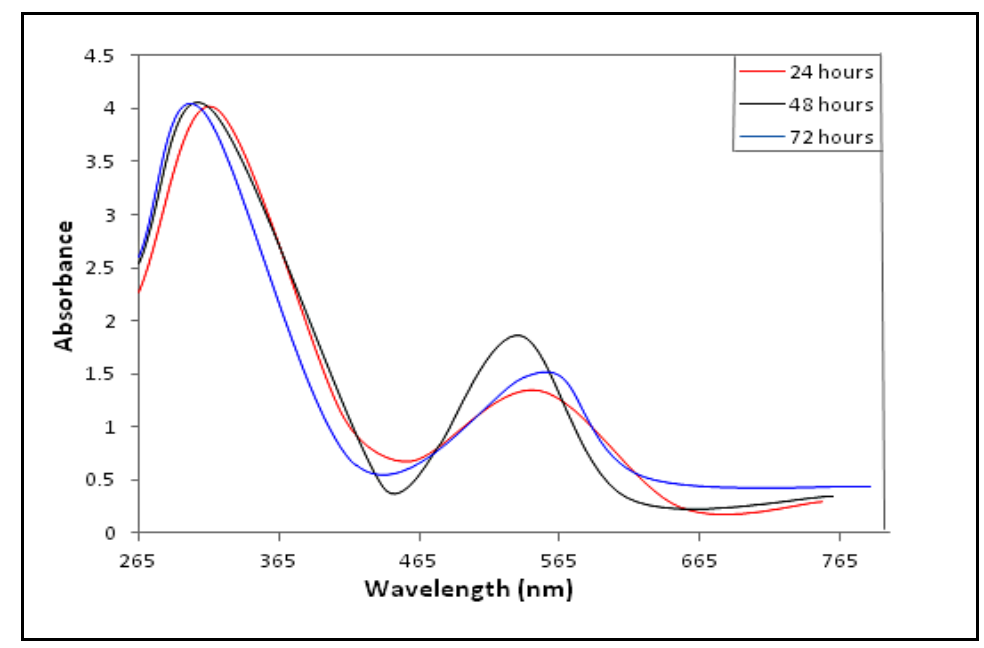

Figure 2. UV-Vis spectra of $\mathrm{P}(\mathrm{ANI}-\mathrm{co}-\mathrm{m}-\mathrm{ABA})$ at 24,48 and 72 hours

Figure 3 and Figure 4 show FT-IR spectra of composite film of the copolymer at different concentrations of monomers and polymerization time. As shown in the spectra of all samples the peaks are approximately presented at $700,1000,1250,1490,1570 \mathrm{~cm}^{-1}$. The main peaks at $1490 \mathrm{~cm}^{-1}$ can be associated with $\mathrm{C}=\mathrm{N}$ and $\mathrm{C}=\mathrm{C}$ stretching vibrations of quinone and benzene rings in PANI chains. The peaks at $1250 \mathrm{~cm}^{-1}$ are attributed to the C-N stretching mode and the vibration of $\mathrm{C}-\mathrm{H}$ in benzene ring. The peak at $1000 \mathrm{~cm}^{-1}$ is due to quinonoid unit of doped PANI. These related peaks confirm the successfully formation of PANI at different monomers ratios. The carbonyl group, $\mathrm{C}=\mathrm{O}$ can be observed in the region in between $1500 \mathrm{~cm}^{-1}$ to $1600 \mathrm{~cm}^{-1}$. The FT-IR results confirming the incorporation of $m$-ABA into polymer backbone due to copolymerization of aniline and $m$-ABA, thus proving that there is carboxylic group presence in the polymer structure. Both of the spectra in Figure 3 and Figure 4 assign the bands in between $650-750 \mathrm{~cm}^{-1}$ and $500 \mathrm{~cm}^{-1}$ in which indicates the presence of $\mathrm{N}-\mathrm{H}$ bending, $\mathrm{C}-\mathrm{H}$ bending inplane and out-plane respectively [9]. The FTIR spectra of PS/P(ANI-co-m-ABA) composite nanofibers is not shown here because it is very similar to PS/P(ANI-co-m-ABA) composite film.

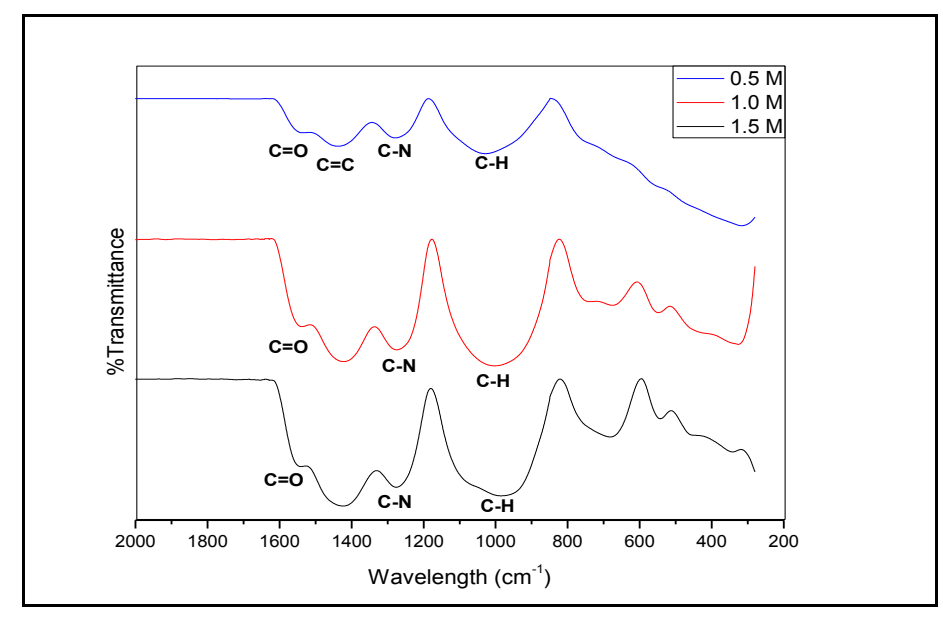

Figure 3. FTIR spectra of PS/P(ANI-co-m-ABA) film at different concentrations of monomer 


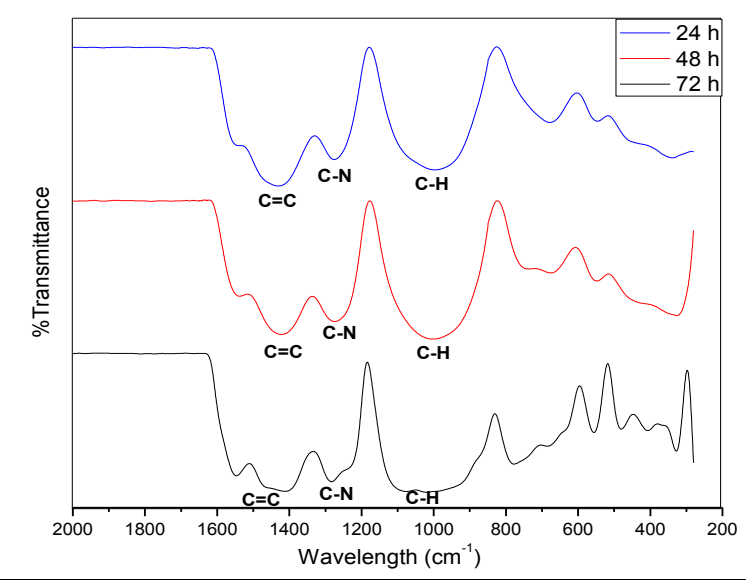

Figure 4. FTIR spectra of PS/P(ANI-co-m-ABA) composite film at different polymerization times

\section{Thermal study of the P(ANI-co-m-ABA)/PS composite nanofiber}

Figure 5 and Figure 6 represent the TGA thermograms for P(ANI-co-m-ABA)/PS at different polymerization times and different concentrations of monomers, respectively. Figure 5 and Figure 6 shows three degradation steps of $\mathrm{PS} / \mathrm{P}\left(\mathrm{ANI}-\mathrm{co}-\mathrm{m}\right.$-ABA) composite nanofibers. The composite shows a weight loss of $7-8 \%$ up to $100{ }^{\circ} \mathrm{C}$, a weight loss of $22 \%$ from $100-450{ }^{\circ} \mathrm{C}$ and a weight loss of $40 \%$ from $450-800^{\circ} \mathrm{C}$. Our data are found in good agreement with the data reported in literature $[10,11]$ which confirms the reliability of our results. When P(ANI-co-m-ABA) was polymerized onto PS nanofiber at different monomer concentration and polymerization time, a different thermal behaviour with respect to the parent polymer, i.e. PANI are shown in figures below. Thermogram suggests that weight loss mainly occurs in two steps. First step corresponds to the loss of water molecules, slow removal of oligomers and loss of impurities up to $120^{\circ} \mathrm{C}$ with a total weight loss of $6 \%$ at ratio concentration of monomer to monomer $0.5 \mathrm{M}$, up to $150^{\circ} \mathrm{C}$ with a weight loss of $9 \%$ in $1.0 \mathrm{M}$ and up to $100{ }^{\circ} \mathrm{C}$ with a weight loss of $12 \%$ in 1.5 M. Second weight loss is due to the expulsion of oxidizing agent, ammonium persulphate (APS).

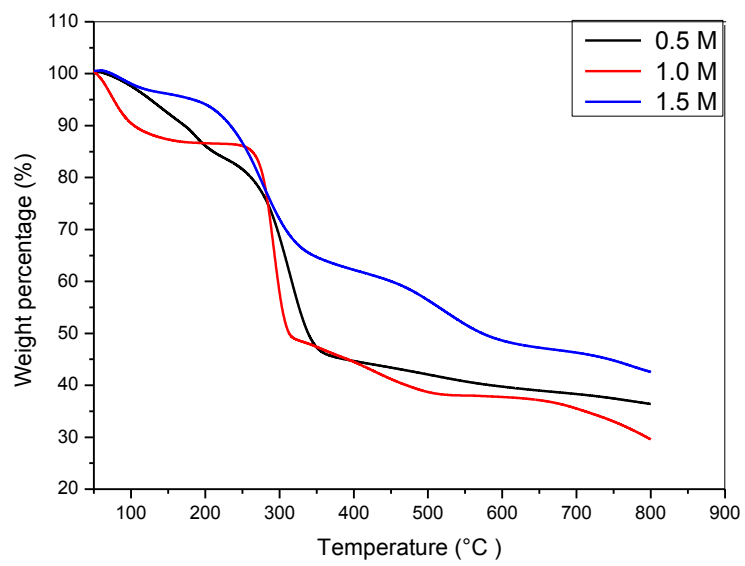

Figure 5. TGA thermograms of $\mathrm{P}(\mathrm{ANI}-\mathrm{co}-\mathrm{m}-\mathrm{ABA}) / \mathrm{PS}$ composite nanofibers at different concentrations of monomers 


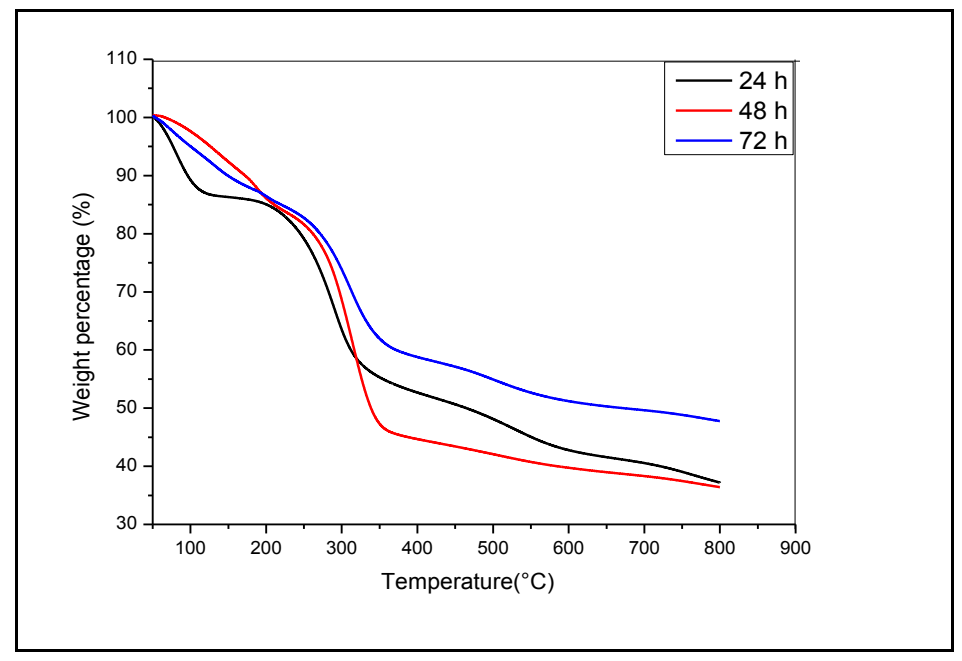

Figure 6. TGA thermograms of $\mathrm{P}(\mathrm{ANI}-\mathrm{co}-\mathrm{m}$-ABA)/PS composite nanofibers at different polymerization times

For P(ANI-co-m-ABA)/PS at $0.5 \mathrm{M}$ and $1.5 \mathrm{M}$, the weight losses of polymer had occurred at $200{ }^{\circ} \mathrm{C}$ to $350{ }^{\circ} \mathrm{C}$ whereas for $\mathrm{P}(\mathrm{ANI}-\mathrm{co}-\mathrm{m}-\mathrm{ABA}) / \mathrm{PS}$ at $1.0 \mathrm{M}$, it occurred at $270{ }^{\circ} \mathrm{C}$ to $330{ }^{\circ} \mathrm{C}$. Third step corresponds to the degradation of polymeric backbone and polystyrene ions in the range of $300-400{ }^{\circ} \mathrm{C}$ (weight loss of ca. $13 \%$ ) in $0.5 \mathrm{M}$, in the range of $300-500^{\circ} \mathrm{C}$ (weight loss ca. $25 \%$ ) in $1.0 \mathrm{M}$, and in the range of $140-360^{\circ} \mathrm{C}$ (weight loss of ca. $38 \%$ ) in $1.5 \mathrm{M}$. Thus, the thermal stabilities of all the composites are considerably less than that of polyaniline. This may be attributed to the decreased chain length and presence of bulky groups in the composites. PS shows a negligible weight loss up to $350{ }^{\circ} \mathrm{C}$ and a continuous weight loss (ca. $15 \%$ ) is observed up to $650{ }^{\circ} \mathrm{C}$, which is possibly due to the degradation of PS in its thermogram. The explanation for thermograms of P(ANI-co-m$\mathrm{ABA}) / \mathrm{PS}$ at different polymerization time is almost similar to the explanation for $\mathrm{P}(\mathrm{ANI}-\mathrm{co}-\mathrm{m}$-ABA)/PS with different concentration. From figure 6, initial weight loss occurred because the water loss whereas the second weight loss happened because of expulsion of APS and then degradation of P(ANI-co-m-ABA).

\section{Surface morphology of the composite film and nanofibers}

Figure 7(a) and (b) show the surface morphology of the PS/GP films before and after coated with copolymer respectively. Based on the results from thermal analysis, PS/P(ANI-co-m-ABA) composite films and nanofibers were prepared using $0.5 \mathrm{M}$ concentration of monomers and 24 hours' polymerization time. Figure 7(a) shows the PS film before undergoes in situ polymerization. There are pores presences on the surface of PS films due to the presence of air bubble inside the films. The other reasons of formation of holes on the surface of PS films may be due to the solvent DMF evaporate slowly to the surrounding during drying process. While Figure 7(b) shows the image of PS films after being coated with copolymer. The presence of copolymer can be seen as the surface of the PS film become rough and the absence of the pores is because the pores are fully covered by the copolymers. The Figure 7(b) also shown that P(ANI-co-m-ABA) has been completely and uniformly coated the surface of PS films.

Figure 8(a) and (b) show SEM images of $10 \%$ and $15 \%$ PS nanofibers before coated with copolymer. PS nanofibers appear to be long, thin and small in diameter. PS nanofiber has larger surface area compare to PS films due to its built up from small diameter of fibers. These special properties of nanofibers will enhance and wider its application in industry such as filter, membrane, drug delivery and many more. Figure 8(c) and (d) show the image of PS nanofiber after been coated with copolymer. The surface of the nanofiber becomes rough and thicker indicates the presence of the P(ANI-co-m-ABA). $10 \%$ PS nanofiber has higher thickness of coating compare to $15 \%$ PS nanofiber due to its small diameter which is $0.15 \mu \mathrm{m}$ compare to $15 \%$ with diameter $0.21 \mu \mathrm{m}$. The smallest 
diameter has higher surface to volume ratio thus increasing the amount of copolymer can be deposited onto the nanofiber. The last Figure 9(a) and (b) shows the surface morphology of the PS/GP films before and after coated with copolymer. The image of PS/GP films is quite similar to the image of PS films where the surface of the film is smooth with the presence of some air bubble trapped inside the film. After copolymer is coated on top of PS/GP film, the surface of the film becomes rough and become thicker too.
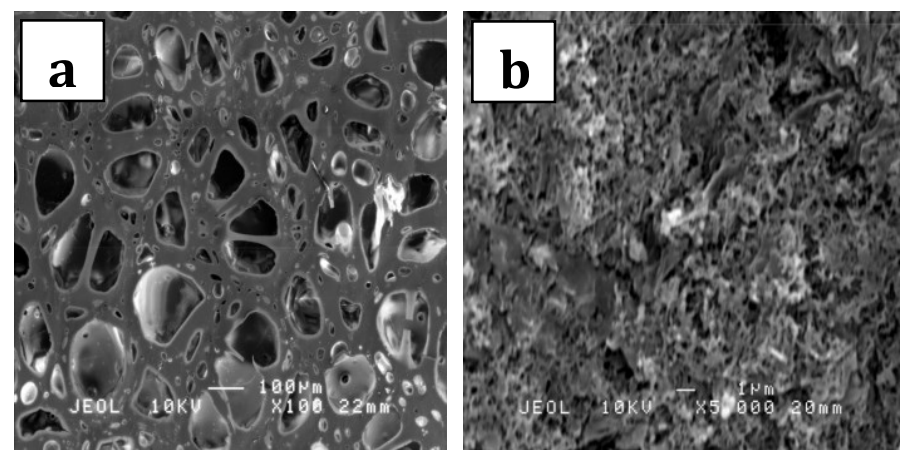

Figure 7. SEM image of (a) PS film and (b) P(ANI-co-m-ABA)/ PS film
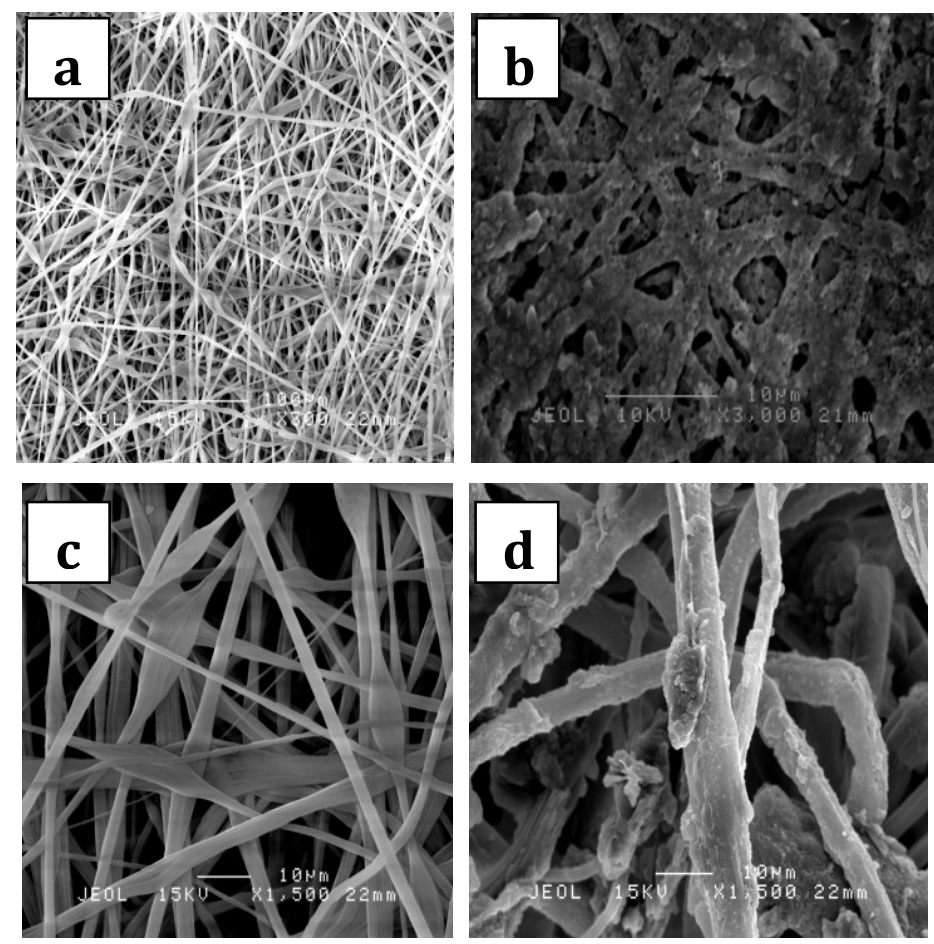

Figure 8. SEM image of (a) $10 \%$ PS nanofiber, (b) P(ANI-co-m-ABA)/ $10 \%$ PS nanofiber, (c) $15 \%$ PS nanofiber and (d) P(ANI-co-m-ABA)/ $15 \%$ PS nanofiber 

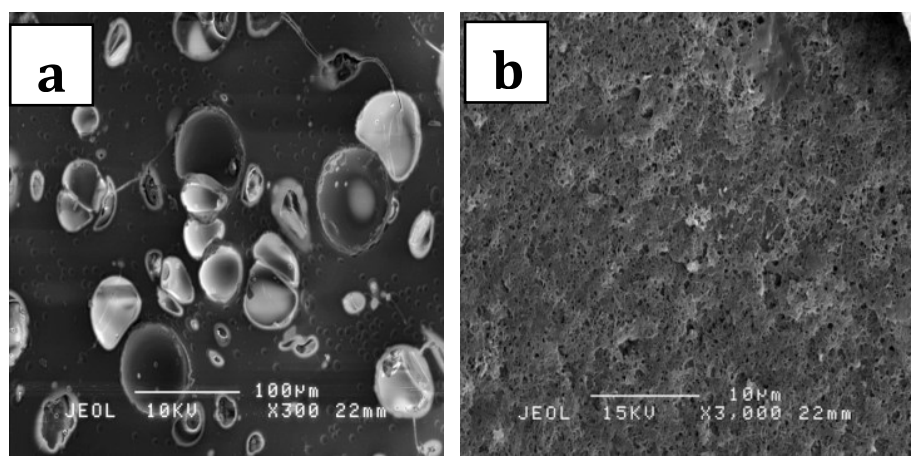

Figure 9. SEM image of (a) PS/graphene film and (b) P(ANI-co-m-ABA)/ PS/graphene film.

\section{Electrical conductivity of the composite fibers}

Electrical conductivity was measured by four-probe method (Stejskal and Gilbert 2002). Table 1 shows the conductivity values for PS nanofiber before and after coated with copolymer. Both of PS nanofiber at $10 \%$ and 15 $\%$ before undergoes in situ polymerization show no conductivity value which indicates that PS nanofibers have no electrical conductivity. The copolymer coated of $\mathrm{P}(\mathrm{ANI}-\mathrm{co}-\mathrm{m}-\mathrm{ABA}) / \mathrm{PS}$ nanofibers showed the conductivity of $\mathrm{PS} / \mathrm{P}\left(\mathrm{ANI}-\mathrm{co}-\mathrm{m}-\mathrm{ABA}\right.$ ) nanofibers up to $0.26 \mathrm{~S} \mathrm{~cm}^{-1}$ for $10 \% \mathrm{PS}$ and $0.17 \mathrm{~S} \mathrm{~cm}^{-1}$ for $15 \%$ PS. The composite of copolymer with PS nanofiber increase the conductivity values thus indirectly will increase the electrical conducting properties of PS as well.

Table 1. Conductivity measurement of $\mathrm{P}(\mathrm{ANI}-\mathrm{co}-\mathrm{m}-\mathrm{ABA}) / \mathrm{PS}$ fiber composite

\begin{tabular}{lc}
\hline Sample & Conductivity $\left(\mathbf{S ~ c m}^{-1}\right)$ \\
\hline $10 \%$ PS fiber & 0.00 \\
P(ANI-co-m-ABA)/10 \% PS fiber & 0.26 \\
$15 \%$ PS fiber & 0.00 \\
P(ANI-co-m-ABA)/15 \% PS fiber & 0.17 \\
\hline
\end{tabular}

Table 2 demonstrates the value of conductivity of PS film when graphene is added into the polymer film. Graphene is well known material that can conduct electrical with great efficiency. Incorporation of graphene into PS film increases the conductivity value. The conductivity value for PS film after adding graphene increased to $0.74 \mathrm{Scm}^{-1}$.

Table 2. Conductivity measurement of P(ANI-co-m-ABA)/PS/GP composite films

\begin{tabular}{lc}
\hline Sample & Conductivity $\left(\mathbf{S ~ c m}^{-\mathbf{1}}\right)$ \\
\hline PS film & -0.25 \\
P(ANI-co-m-ABA)/PS/GP films & 0.74 \\
\hline
\end{tabular}

\section{Conclusion}

In this work, $\mathrm{P}(\mathrm{ANI}-\mathrm{co}-\mathrm{m}-\mathrm{ABA})$ was deposited on PS film and nanofiber using in situ polymerization method. The composites were synthesized varying the amount of aniline and $m$-ABA in the composites and also varying the polymerization time. The copolymer was incorporated on PS nanofiber to become composite, hence increasing the mechanical strength and electrical properties of the whole polymer. The structures were confirmed by FT-IR 
spectroscopy. The copolymer formation was confirmed by UV-Vis spectroscopy and electrical measurements. The surface morphology showed a nanofibrous structure. The conductivity of the composite increased with the addition of graphene.

\section{Acknowledgement}

The authors gratefully acknowledge to Dr Lim Hong Ngee for the supply of rGO. The authors also would like to acknowledge the financial support from the Ministry of Higher Education and Graduate Research Fellowship for the sponsorship.

\section{References}

1. Bahgat, A. A., Sayyah, S. M., and Abd-Elsalam, H. M. (2003). Study of ferroelectricity in polyaniline. International Journal of Polymeric Materials and Polymeric Biomaterial, 52(6): 499 - 515.

2. Abdul Rahman, N., Gizdavic-Nikolaidis, M., Ray, S., Eastal, A. J., Travas-Sejdic, J. (2010). Functional electrospun nanofibres of poly(lactic acid) blends with polyaniline or poly(aniline-co-benzoic acid), Synthetic Metals, 160: 2015 - 2022.

3. Ashran, V., Seydewitz, V. and Michler, G.H. (2011). Micromechanical properties and ductile behavior of electrospun polystyrene nanofibers, Applied Polymer Science, 135: 1663 - 1673.

4. Tahir, Z., Alocilja, E. C. and Grooms, D. L. (2005). Polyaniline synthesis and its biosensor application. Biosensors and Bioelectronics, 20: 1690 - 1695.

5. Stejskal, J. and Gilbert, R. G. (2002). Polyaniline: preparation of a conducting polymer. Pure Applied Chemistry, 74(5): $857-867$.

6. Gerard, M., Chaubey, A. and Malhotra, B. D. (2002). Application of conducting polymers to biosensors. Biosensors and Bioelectronics, 17: 345 - 359.

7. Gospodinova, N. and Terlemezyan, L. (1998). Conducting polymers prepared by oxidative polymerization:polyaniline. Progress Polymer Science, 23: 1443 - 1484.

8. Huang, Z.-M., Zhang, Y. Z., Kotaki, M. and Ramakrishna, S. (2003). A review on polymer nanofibers by electrospinning and their applications in nanocomposites. Composite Science and Technology, 63: $2223-$ 2253.

9. Inzelt, G. (2008). Conducting polymers: A new era in electrochemistry. Berlin: Springer, 53: 123 - 135.

10. Wang, S., Tan, Z., Li, Y., Sun, L. and Zhang, T. (2006). Synthesis, characterization and thermal analysis of polyaniline/zro2 composites. Thermochimica Acta, 44: 191 - 194.

11. Wu, C. G., Liu, Y. C. and Hsu, S. S. (1999). Assembly of conducting polymer/metal oxide multilayer in one step. Synthetic Material, 102: 1268 - 1269. 